\title{
Effects of oxytocin on sperm transport in the pubertal rat
}

\author{
J. Frayne, D. Townsend and H. D. Nicholson* \\ Department of Anatomy, University of Bristol, Southwell Street, Bristol BS2 8EJ, UK
}

\begin{abstract}
Oxytocin is present in the mammalian testis where it increases contractility of seminiferous tubules in vitro and has been implicated in sperm transport. The present study investigated whether oxytocin affects the transport of spermatozoa from the testis in vivo. In rats, mature spermatozoa are first seen in the testis 42 days postpartum and arrive in the epididymis at about day 45. Male Wistar rats were given daily subcutaneous injections of either oxytocin $(0.5 \mu \mathrm{g})$, the oxytocin antagonist des $\mathrm{Gly}-\mathrm{NH}_{2} \mathrm{~d}\left(\mathrm{CH}_{2}\right)_{5}-\left[\mathrm{D}-\mathrm{Tyr}^{2}, \mathrm{Thr}^{4}\right] \mathrm{OVT}(0.2 \mu \mathrm{g})$ or saline from day 40 postpartum. Groups of six animals were killed $2 \mathrm{~h}$ after their last injection on days $43,44,45$ and 46 postpartum. Testes were removed and fixed in Bouin's fluid for histological examination and the number of spermatozoa in the epididymides was counted. Spermatozoa were seen in the epididymis earlier in the oxytocin-treated rats (day 43) than in the control animals (day 44), and treatment with the antagonist delayed the appearance of spermatozoa in the epididymis until day 45 . When the testes were examined, residual bodies, which were used as an indicator of spermiation, were seen only in one control animal before day 44 . Residual bodies were seen in the testes of all oxytocin-treated rats on day 43 but were not detected until day 45 in the oxytocin antagonist-treated rats. These data show that in rats oxytocin can affect the arrival of spermatozoa in the epididymis. Although this may be due in part to effects on tubal transport or the secretion of tubular fluid, these findings suggest that the peptide may affect spermiation.
\end{abstract}

\section{Introduction}

The peptide oxytocin is present in the mammalian testis (Nicholson et al., 1984) and in the rat is produced by Leydig cells (Guldenaar and Pickering, 1985; Nicholson and Hardy, 1992). In the female reproductive tract, the effects of oxytocin on smooth muscle contractility have been well documented and a similar function has been demonstrated in the male (Niemi and Kormano, 1965; Pickering et al., 1990).

The rat testis consists of a number of seminiferous tubules within which spermatogenesis occurs. Spermatogenesis is a highly complex and organized process that results in the shedding of spermatozoa into the tubular lumen. Spermatozoa are transported to the epididymis where motility is acquired. This transport is thought to occur owing to a combination of fluid secretion by the seminiferous epithelium and to the contractile activity of the tubules which are surrounded by a layer of smooth muscle-like cells, the myoid cells (Bedford, 1975). Seminiferous tubules are spontaneously contractile in vitro (Roosen-Runge, 1951) and this contractility can be increased by the administration of oxytocin (Niemi and Kormano, 1965) at concentrations similar to those found in the testis (Worley et al., 1985). Furthermore, depletion of testicular oxytocin, as induced by the drug ethane dimethane sulfonate

*Correspondence.

Received 10 January 1996. which destroys Leydig cells, is accompanied by a decrease in the spontaneous contractility of the tubules; however, contractile activity can be restored by the addition of exogenous oxytocin (Nicholson et al., 1987). A role for oxytocin in the regulation of tubule contractility is also supported by the demonstration that the peptide can be detected in the testis only when there is active spermatogenesis. Thus, testicular oxytocin is not present in sex-reversed mice which lack germ cells (Pickering et al., 1986). In neonatal rats, oxytocin does not appear until spermatogenesis is established (Worley et al., 1985), and disruption of spermatogenesis induced by local heating produces a decrease in testicular oxytocin. However, although there is evidence that oxytocin may have a paracrine role in the regulation of seminiferous tubule contractility, the functional significance of this with respect to its effects on sperm transport still remains to be established.

This study was performed to determine whether oxytocin can increase the transport of spermatozoa from the testis to the epididymis in rats. Pubertal rats were chosen so that the appearance of spermatozoa in the epididymis could be used as a marker of transport, and also correlate the onset of transport with the presence of oxytocin within the testis. In adult rats it takes an average of 53.2 days for a primary spermatogonium to differentiate into a spermatozoon. This process is shorter in prepubertal animals, and mature spermatids are present in the testis on day 42 (Van Haaster and de Rooij, 1993) and spermatozoa are detectable in the epididymis by day 45 
postpartum. In the present study, oxytocin, or a specific oxytocin antagonist, was administered daily from day 40 postpartum and the appearance of spermatozoa in the epididymis was studied. In a second experiment, the chronological appearance of oxytocin in the normal prepubertal rat was investigated using immunohistochemistry.

\section{Materials and Methods}

Male, Wistar rats were used in all experiments. The animals were housed under a controlled temperature and light regimen (14 h light:10 $\mathrm{h}$ dark) and given food and water ad libitum.

Experiment 1: the effect of oxytocin on the appearance of spermatozoa in the epididymis of pubertal rats

Rats were given daily, subcutaneous injections of either $0.5 \mu \mathrm{g}$ oxytocin (Cambridge Research Biochemicals Ltd, Cambridge), $0.2 \mu \mathrm{g}$ oxytocin antagonist des $\mathrm{Gly}-\mathrm{NH}_{2} \mathrm{~d}\left(\mathrm{CH}_{2}\right)_{5}-$ [D-Tyr ${ }^{2}, T^{4}{ }^{4}$ OOVT (Manning et al., 1995), or saline, from day 40 postpartum. The oxytocin antagonist was kindly provided by M. Manning (Department of Biochemistry and Molecular Biology, Medical College of Ohio, Toledo, $\mathrm{OH}$ ). Groups of six control animals were killed by cervical dislocation $3 \mathrm{~h}$ after their last injection on days $43,44,45$ and 46 postpartum. Groups of six oxytocin-treated rats were killed on days 43-45 and antagonist-treated animals on days 44-46. Trunk blood was collected from all animals for hormone estimation.

\section{Epididymal sperm counts}

Epididymal sperm counts were performed using the method of Taylor et al. (1985). The epididymides were removed and minced in $1 \mathrm{ml} 0.9 \%(\mathrm{w} / \mathrm{v}) \mathrm{NaCl}$. Aliquots of the resulting sperm suspension were then counted in a haemocytometer.

\section{Histology}

Testes were fixed in Bouin's fluid and then processed for light microscopy. Sections $(5 \mu \mathrm{m})$ were cut and stained with haematoxylin and eosin. During development of mature spermatozoa there is remodelling of the spermatid and movement of its cytoplasm away from the flagellum. This cytoplasm, containing redundant organelles, is shed by the spermatid when it leaves the seminiferous epithelium and appears as the residual body. The presence of residual bodies was used as an indication that spermiation had occurred and that spermatozoa have been shed from the seminiferous epithelium. Where residual bodies were present, 100 tubules in each section were examined and the number of tubules which contained residual bodies was expressed as a percentage of the tubules examined.

\section{Hormone radioimmunoassays}

Testosterone. Testosterone was extracted from plasma samples using diethylether (Yeung et al., 1988). Testosterone concentrations in plasma were measured as described by Yeung et al. (1988). The limit of detection was $0.7 \mathrm{nmol} \mathrm{I}^{-1}$.
LH. Plasma concentrations of LH were measured using reagents provided by NIADDK. The tracer was prepared by the chloramine-T method (Greenwood et al., 1963) using peptide rLH-I-9. All samples were assayed at one time.

FSH. Plasma concentrations of FSH were measured using reagents supplied by NIADDK as described by Nicholson et al. (1991).

\section{Experiment 2: the appearance of oxytocin in the testis of young} rats

Rats were killed on days $3-20$ and $28-45$ postpartum. Testes were removed and fixed in modified Bouin's solution (Guldenaar and Pickering, 1985). Immunocytochemistry was performed on $5 \mu \mathrm{m}$ sections using antiserum RI6, kindly donated by I. C. A. F. Robinson (Mill Hill, London). Sections were incubated overnight with the oxytocin antiserum RI6 at a dilution of $1 / 200$ at $4^{\circ} \mathrm{C}$. The sections were then washed and the secondary antibody, peroxidase-conjugated swine anti-rabbit immunoglobulins (Dakopatts, High Wycombe), was applied for $2 \mathrm{~h}$ at room temperature. Sections were then exposed to the substrate hydrogen peroxide and diaminobenzidine to visualize the immunoreactive oxytocin.

The procedure was performed on three separate occasions with a section from each testis included each time to minimize variation in the intensity of staining observed. On each occasion sections from an adult rat testis were included. Further controls included sections incubated with either normal rabbit serum or oxytocin antiserum preabsorbed with oxytocin in place of the primary antiserum.

\section{Statistical analyses}

Data were analysed by analysis of variance and if interaction was found, differences between the means were tested for significance by use of Student's $t$ test. The numbers of epididymides containing spermatozoa were compared using the chi-squared test.

\section{Results}

Experiment 1: the effect of oxytocin on the appearance of spermatozoa in the epididymis of pubertal rats

Treatment with oxytocin had no effect on the body mass of the animals (Table 1). Although the body masses of the animals that received the oxytocin antagonist were lower, the reduction was not significant compared with control values. Although testicular masses were similar in the control and oxytocin-treated animals, rats that received the oxytocin antagonist had significantly lighter testes $(P<0.05)$. Epididymal masses were similar in all groups, except on day 43 when the masses were increased in the oxytocin-treated animals $(P<0.05$; Table 1$)$.

\section{Epididymal sperm counts}

No spermatozoa were seen in the epididymides of five of the six animals in the control group examined on day 43 , and only 
Table 1. The effect of daily injections of either saline, oxytocin or oxytocin antagonist given to rats from day 40 postpartum on body, testicular and epididymal masses

\begin{tabular}{lcccc}
\hline Treatment & Day 43 & Day 44 & Day 45 & Day 46 \\
\hline Body mass (g) & & & & \\
$\quad$ Saline & $158 \pm 7$ & $176 \pm 13$ & $170 \pm 10$ & $208 \pm 4$ \\
$\quad$ Oxytocin & $161 \pm 6$ & $186 \pm 13$ & $180 \pm 8$ & n.m. \\
$\quad$ Oxytocin antagonist & n.m. & $146 \pm 11$ & $164 \pm 10$ & $184 \pm 15$ \\
Testis mass (g) & & & & \\
$\quad$ Saline & $0.86 \pm 0.05$ & $1.19 \pm 0.06$ & $1.16 \pm 0.06$ & $1.24 \pm 0.02$ \\
$\quad$ Oxytocin & $0.83 \pm 0.04$ & $1.22 \pm 0.07$ & $1.20 \pm 0.05$ & n.m. \\
$\quad$ Oxytocin antagonist & n.m. & $0.89 \pm 0.04$ & $0.96 \pm 0.05$ & $1.05 \pm 0.06^{*}$ \\
Epididymal mass (g) & & & & $0.17 \pm 0.005$ \\
$\quad$ Saline & $0.12 \pm 0.01$ & $0.17 \pm 0.01$ & $0.15 \pm 0.01$ & n.m. \\
$\quad$ Oxytocin & $0.16 \pm 0.01^{* *}$ & $0.17 \pm 0.005$ & $0.16 \pm 0.02$ & $0.13 \pm 0.02$ \\
$\quad$ Oxytocin antagonist & n.m. & $0.15 \pm 0.01$ & $0.12 \pm 0.02$ & \\
\hline
\end{tabular}

Masses shown represent a single testis or epididymis per animal. Values are means $\pm \operatorname{sEM}, n=6$. n.m.: not measured. ${ }^{*} P<0.05$ (ANOVA); $* * P<0.05$ when compared with control value at day 43 ( $t$ test).

18 spermatozoa were observed in the sixth animal $(P<0.008$; $\chi^{2}$ test). Spermatozoa were present in the epididymides of all the control rats on day 44 and increased in number over the next 2 days (Fig. 1a). In animals that received oxytocin, spermatozoa were present in all the epididymides examined on day 43 postpartum (Fig. 1b). Sperm counts increased over the period of study and at all times were higher than those seen in the control animals $(P<0.05)$. Administration of the oxytocin antagonist significantly delayed the appearance of spermatozoa in the epididymis. No spermatozoa were observed on day 44 postpartum (Fig. Ic) and significantly fewer compared with the control group were seen on day $45(P<0.01)$.

\section{Histology}

Residual bodies were seen in the testes from only one animal in the control group killed on day 43; this was the same animal in which spermatozoa were present in the epididymis. In the remaining five animals no residual bodies were seen (Fig. 2a) and the most advanced stage of the spermatogenic cycle observed contained step 18 spermatids (Fig. 3a). Residual bodies were seen in the testes of all control animals killed on days 44 (Fig. 3c), 45 and 46 . Unlike the control animals, residual bodies were seen in all the oxytocin-treated rats on day 43 (Figs 2b, 3b) and on subsequent days (Fig. 3). Residual bodies were not seen in any of the animals that received oxytocin antagonist until day 45 postpartum (Fig. 2c); even then the number of tubules in which residual bodies were seen (Fig. 3d) was significantly less $(P<0.05)$ than that of control animals. No residual bodies were seen in 44-day-old oxytocin antagonist-treated rats and the most advanced stage present contained step 18 spermatids (Fig. 3e).

Sections were also examined to determine whether in rats administered oxytocin or its antagonist spermiation had occurred at stage VIII, as expected, or whether spermatozoa were being shed at an inappropriate stage of the spermatogenic cycle. Residual bodies were not observed before stage VII-VIII of the cycle and the pattern of cellular associations was similar to that seen in control animals (Fig. 3b, c, e).

\section{Hormone measurements}

No consistent significant differences in plasma concentrations of LH or testosterone were seen between the three treatment groups during the study (data not shown). However, while administration of oxytocin did not affect plasma FSH concentrations, treatment with the antagonist reduced concentrations of FSH on day 44 (control $2.46 \pm 0.62 \mathrm{ng} \mathrm{ml}^{-1}$; oxytocin $2.34 \pm 0.64 \mathrm{ng} \mathrm{ml}{ }^{-1}$; oxytocin antagonist $0.93 \pm 0.43 \mathrm{ng} \mathrm{ml}^{-1}$ ) and day 45 (control $3.27 \pm 0.74 \mathrm{ng}$ $\mathrm{ml}^{-1}$; oxytocin $3.56 \pm 0.54 \mathrm{ng} \mathrm{ml}^{-1}$, oxytocin antagonist $<0.5 \mathrm{ng} \mathrm{ml}^{-1}$ ).

\section{Experiment 2: the appearance of oxytocin in the testes of young} rats

In the adult testis, discrete staining was localized in the interstitial tissue (Fig. 4a). Incubation of sections with either normal rabbit serum, instead of the primary antibody, or with the anti-oxytocin serum preabsorbed with oxytocin, abolished this staining (Fig. $4 \mathrm{~b}$ ). In the immature animals no staining for oxytocin was seen before day 30 postpartum (Fig. 4c). Faint staining of the interstitial tissue was seen from day 31 postpartum (Fig. 4d). The oxytocin-specific interstitial staining increased in intensity between day 40 and day 43 (Fig. 4e). This increase in staining occurred when the most mature germ cells present were stage 18 spermatids, stage VI. No difference in the depth of staining was seen between day 45 and day 46 and the appearance was similar to that seen in the adult testis.

\section{Discussion}

We have previously shown that oxytocin can modulate the contractility of seminiferous tubules in vitro (Worley et al., 1985) and that a reduction in testicular oxytocin concentrations is associated with decreased contractile activity of the tubules. The present study provides the first evidence in rats that oxytocin treatment can bring forward the delivery of 


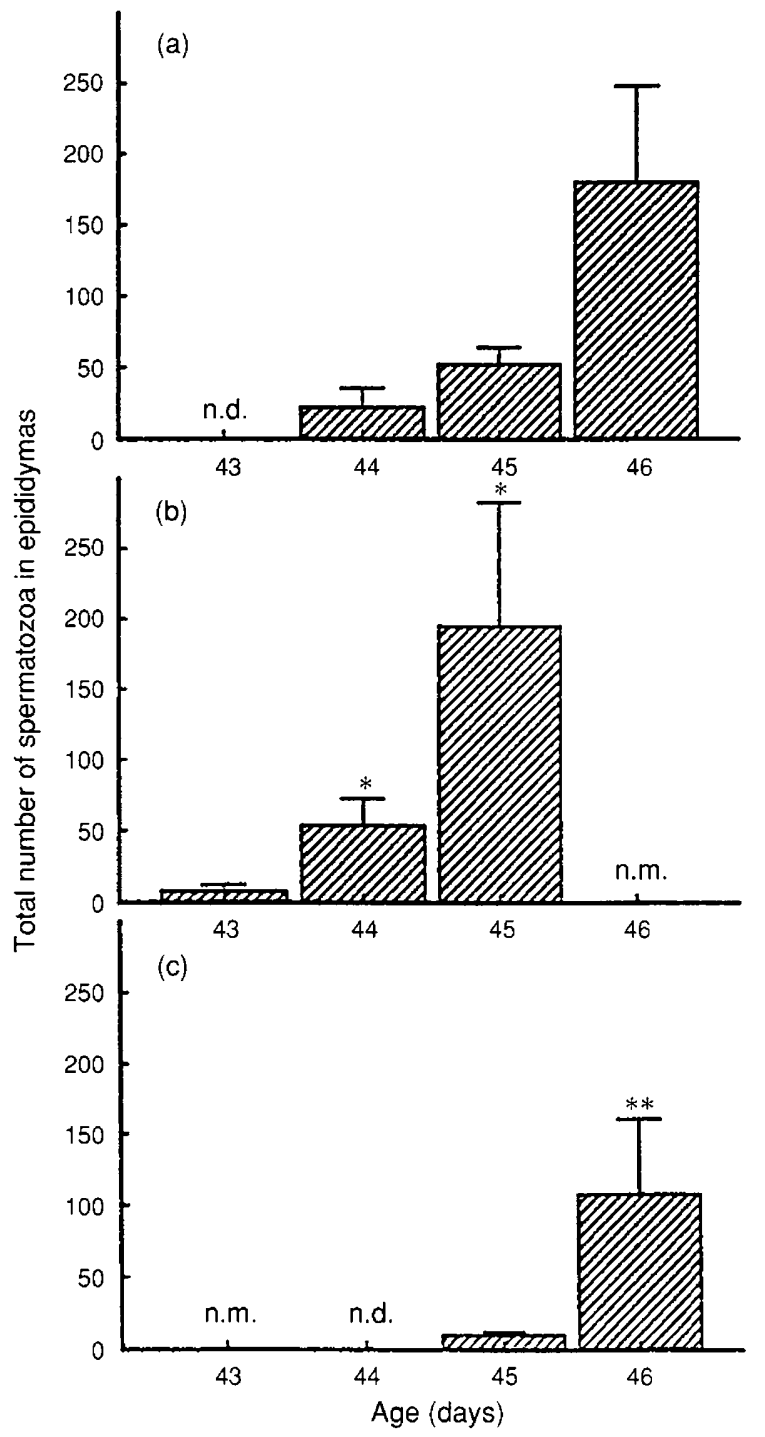

Fig. 1. The appearance of spermatozoa in the epididymis after daily treatment of rats from the age of 40 days with (a) saline, (b) oxytocin or (c) oxytocin antagonist. Bars represent means \pm SEM $(n=6)$. n.m. $=$ not measured; $n . d .=$ not detected. ${ }^{*} P<0.05 ;{ }^{*} P<0.01$; No spermatozoa were found in five of the six saline-treated animals on day 43; however, in one animal, 18 spermatozoa were found in the epididymis.

spermatozoa to the epididymis in vivo. Other workers have demonstrated that exogenous oxytocin can increase sperm transport in the epididymis and ductus deferens of sheep (Knight, 1974) but have not shown that this effect is specific to oxytocin. The demonstration that the antagonist retards the appearance of spermatozoa in the epididymis, that is, opposes the effect of oxytocin, suggests that the oxytocin has a specific action on the seminiferous tubules. Such an effect of oxytocin on sperm transport could be directly related to its observed effect on tubule contractility. However, it may, alternatively, be due to an effect of the peptide on fluid secretion by the seminiferous epithelium, a factor also known to be involved in the sperm transport mechanism (Voglmayr, 1975).

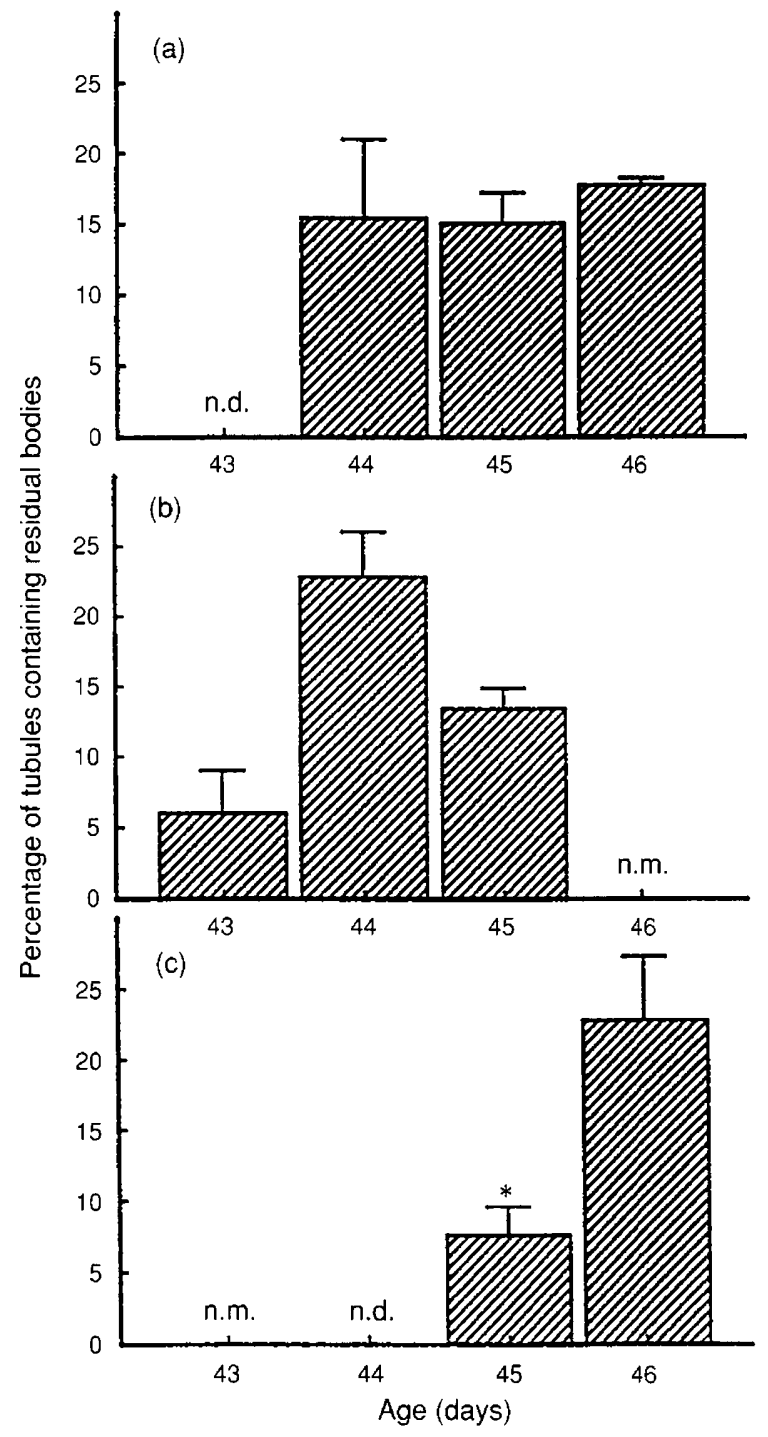

Fig. 2. The presence of residual bodies in the rat testis after daily treatment from the age of 40 days with (a) saline, (b) oxytocin or (c) oxytocin antagonist. Bars represent mean \pm SEM $(n=6)$. n.m.: not measured; n.d: not detected. ${ }^{*} P<0.05$; Residual bodies were present in only one animal in the saline-treated group on day 43 . Spermatozoa were present in the epididymis of the animal.

Tubule contractility has also been implicated in the process of shedding of spermatozoa from the seminiferous epithelium (Gravis, 1980). Our data show that the earlier appearance of spermatozoa in the epididymis of oxytocin-treated animals may not be due solely to a change in sperm transport but may reflect an alteration in the process of spermiation. Residual bodies and, thus, presumably shedding of spermatozoa occur earlier after oxytocin administration and, perhaps more importantly, this process is delayed when an oxytocin antagonist is given. The presence of normal cellular associations within the testis of control and treated animals suggests that spermatozoa are not being shed at an earlier, or later stage, of the spermatogenic cycle, and that the peptides may be affecting the dynamics of the seminiferous epithelium. There is little information in the literature about whether oxytocin affects the 

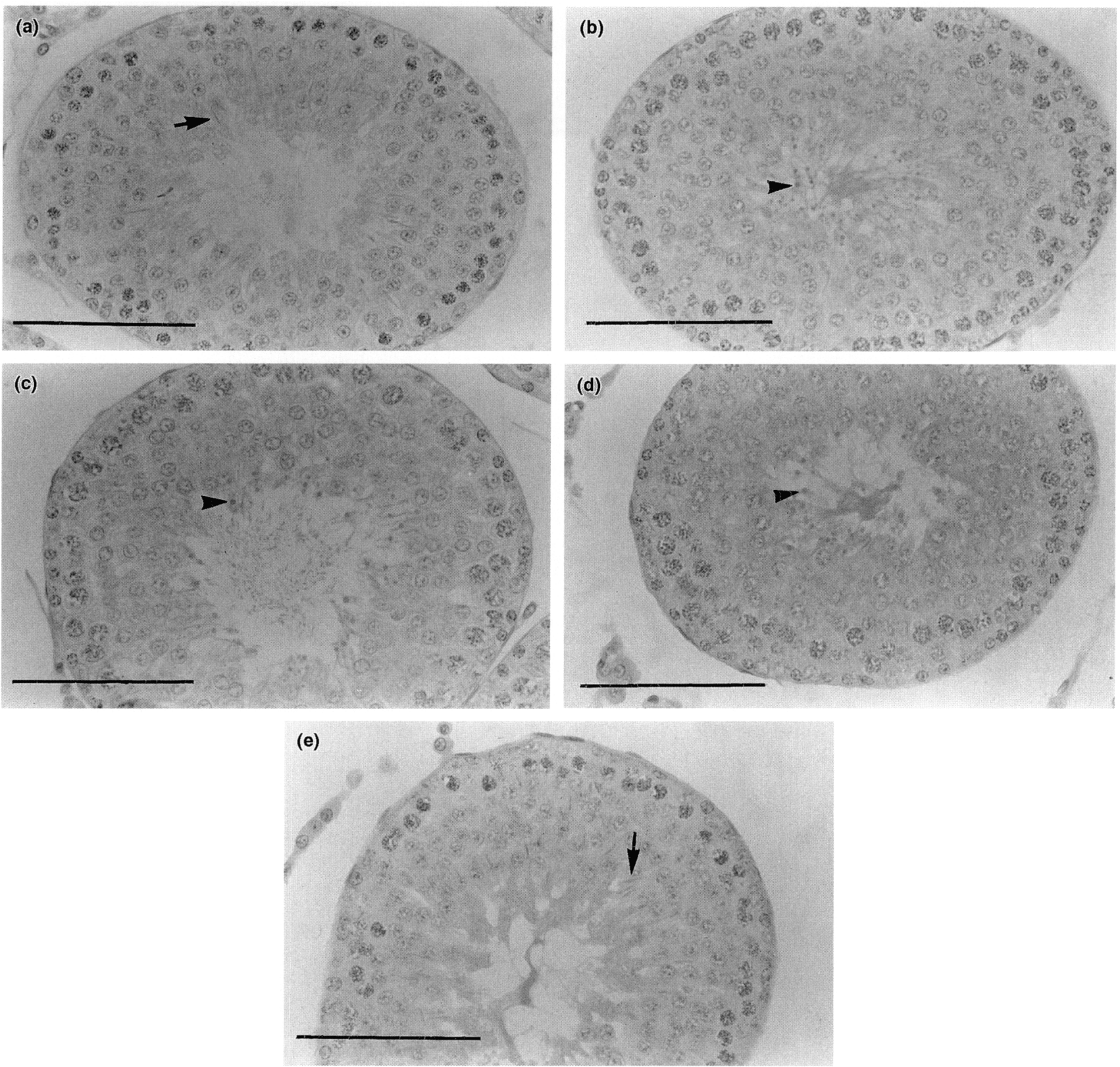

Fig. 3. The effects of oxytocin and an oxytocin antagonist on testicular morphology of pubertal rats. (a) A seminiferous tubule from a 43-day-old saline-treated rat. Spermatids are present embedded in the seminiferous epithelium (arrow); no residual bodies are seen. (b) A seminiferous tubule from a 43-day-old oxytocin-treated rat. Residual bodies are seen at the luminal surface (arrowhead). (c) A seminiferous tubule from a 44-day-old saline-treated rat. Residual bodies are seen (arrow head) and spermatozoa are present in the tubular lumen. (d) A seminiferous tubule from a 45-day-old oxytocin antagonist-treated rat. Residual bodies are present (arrowhead). (e) A seminiferous tubule from a 44-day-old oxytocin antagonist-treated rat. Spermatids are present embedded in the seminiferous epithelium (arrow); no residual bodies are seen. Scale bar represents $0.1 \mathrm{~mm}$.

duration of the spermatogenic cycle in rats, but in mice, a single injection of the peptide on day 21 postpartum has been reported to increase the number of spermatagonia and spermatozoa present in the testis 3 days later (Al-Janabi et al., 1987). How oxytocin affects the seminiferous epithelium is not yet known.

During the development of a spermatozoon, extensive changes occur in the shape of the spermatid and its position within the seminiferous epithelium (Fawcett and Phillips, 1969). Thus, at stage $\mathrm{V}$ of the spermatogenic cycle, spermatids are deeply embedded in the cytoplasm of the Sertoli cells and lie close to the outer wall of the tubule, but have to move to the luminal surface before shedding at stage VIII (4.5 days later in the rat). This movement is accompanied by morphological changes in the spermatid resulting in most of the cytoplasm being left as the residual body. At later stages, the spermatids 

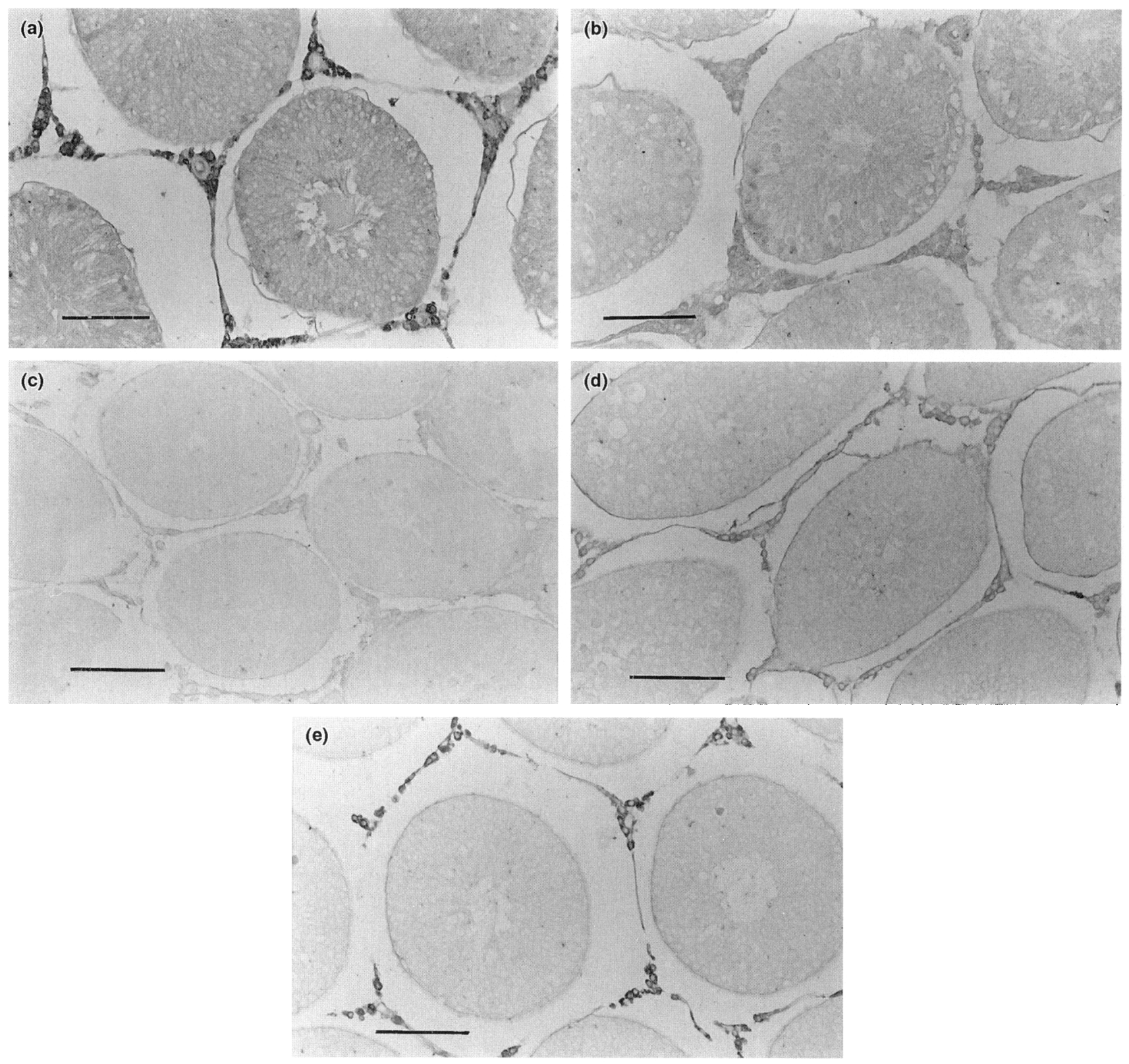

Fig. 4. The appearance of immunoreactive oxytocin in the developing rat testis. (a) Cross section of a testis from an adult rat showing immunostaining for oxytocin in discrete cells of the interstitial tissue. (b) Control cross section of an adult rat testis. Staining is abolished when the primary antiserum is preabsorbed with oxytocin. (c) Cross section of a testis from a 29-day-old rat. No specific staining for oxytocin is seen. (d) Cross section of a testis from a 31-day-old rat. Faint staining for immunoreactive oxytocin is seen in the interstitium. (e) Cross section of a testis from a 43-day-old rat. The staining of cells in the interstitium has increased in intensity and resembles that seen in adults. Scale bar represents $0.1 \mathrm{~mm}$.

are held loosely to the Sertoli cells by cytoplasmic processes, the tubulobulbar complex (Russell and Clermont, 1976). Two types of spontaneous contractile activity are exhibited by seminiferous tubules in vitro; (i) small continual vibratory-like movements and (ii) larger contractions associated with the buik transport of tubular contents. Oxytocin has been shown to increase both of these types of movements (Worley et al., 1985). Although the function of the larger movements has been assumed to be involved with sperm transport, the role of the smaller, vibratory contractions has remained obscure.
However, these latter movements may be involved in moving the developing spermatids from deep within the Sertoli cells to the lumen and in promoting their detachment into the tubular fluid.

Preliminary studies in vitro show that variations in these tubular movements that are related to the stage of the spermatogenic cycle, and the greatest contractility is observed at stage $\mathrm{V}$ (Harris and Nicholson, 1995). Treatment with oxytocin in vivo may increase these movements and produce the earlier shedding of spermatozoa as seen in this study. 
Conversely, treatment with an oxytocin antagonist may decrease, but not abolish (since other factors such as prostaglandins have been implicated as regulators of contractility), tubule contractility, and thus delay the process of spermiation.

There is some controversy about the presence of oxytocin receptors within the testis. Binding sites for oxytocin have been identified on Leydig cells (Bathgate and Sernia, 1994) but not on myoid cells, although our studies of tubular contractility in vitro would suggest that oxytocin has a biological effect on contractility (Pickering et al., 1990). However, $V_{1}$ vasopressin receptors have been identified on rat myoid cells (Howl et al., 1995), and it has been suggested that oxytocin may act via the $V_{1}$ receptor on these cells, although other sites of action of the peptide in the seminiferous epithelium cannot be excluded.

FSH concentrations were reduced after treatment with the oxytocin antagonist. This decrease may explain the lower testicular mass seen in these animals. However, reasons for this change in hormone concentration are not clear. The increase in epididymal mass in oxytocin-treated rats on day 43 may be due to an increase in transport of spermatozoa and fluid in these animals.

In pubertal rats, intense staining for oxytocin is observed shortly before shedding of the first spermatozoa. The trigger for the production of the peptide is not yet known, but we have shown that the seminiferous epithelium is important in regulating testicular oxytocin concentrations (Nicholson et al., 1994). The first appearance of oxytocin at day 30 postpartum may be related to the acquisition of adult type Leydig cells at this time (Hardy et al., 1989). Tubular fluid secretion begins at 30 days postpartum and increases to adult rates at about 40 days (Setcheil, 1970). Further experiments are necessary to investigate whether oxytocin affects tubular fluid secretion, or whether the appearance of oxytocin is associated with an alteration of tubular contractility. The timing of the appearance of oxytocin in the testis, as visualized by immunocytochemistry, differed from our earlier findings when the immunoreactive peptide was detected using a radioimmunoassay on day 8 postpartum (Worley et al., 1985). The radioimmunoassay data may indicate that oxytocin is present in the fluid compartments of the neonatal testis and may not reflect local production of the peptide. Alternatively, the immunoreactivity detected by radioimmunoassay may represent an oxytocin-like peptide that was not detected by the antiserum used for immunocytochemistry.

In conclusion, this study has demonstrated that oxytocin can bring forward the appearance of spermatozoa in the epididymis of pubertal rats, and that this may be due to a specific action of the peptide on the process of spermiation. The appearance of increased concentrations of the peptide shortly before the onset of spermiation suggests that oxytocin plays a physiological role in the shedding of spermatozoa from the seminiferous epithelium and the transport of spermatozoa to the epididymis. Oxytocin may, therefore, play an important role in the control of fertility.

The authors would like to thank M. Manning for the gift of the oxytocin antagonist, I. C. A. F. Robinson for the oxytocin antiserum R16 and NIADDK for the reagents for the rat LH and FSH radioimmunoassays. This work was supported by the Wellcome Trust.

\section{References}

Al-Janabi AS, Zahid ZR and Lazim KA (1987) Stimulation of testicular activity and spermatogenesis in immature mice by oxytocin Indian journal of Experimental Biology 25 293-295

Bathgate RAD and Sernia C (1994) Characterization and localization of oxytocin receptors in the rat testis Journal of Endocrinology $141343-352$

Bedford JM (1975) Maturation, transport and fate of spermatozoa in the epididymis. In Handbook of Physiology, Section 7 Endocrinology Vol 5, Male Reproductive Systems pp 303-317 Eds DW Hamilton and RO Greep. American Physiological Society, Washington, DC

Fawcet DW and Phillips DM (1969) Observations on the release of spermatozoa and on changes in the head during passage through the epididymis Journal of Reproduction and Fertility Supplement 6 405-418

Gravis CJ (1980) Ultrastructural observations on spermatozoa retained within the seminiferous epithelium after treatment with dibutyryl cyclic AMP Tissue and Cell 12 309-322

Greenwood FC, Hunter WM and Glover JS (1963) The preparation of ${ }^{131} \mathrm{I}$ labelled human growth hormone of high specific radioactivity Biochemical Journal 89 114-123

Guldenaar SEF and Pickering BT (1985) Immunocytochemical evidence for the presence of oxytocin in rat testis Cell and Tissue Research 240 485-487

Hardy MP, Zirkin BR and Ewing LL (1989) Kinetic studies on the development of the adult population of Leydig cells in testis of the pubertal rat Endocrinology 124 762-770

Harris G and Nicholson HD (1995) Stage related differences of rat seminiferous tubule contractility in vitro and their response to oxytocin Journal of Reproduction and Fertility Abstract Series 15 Abstract 157

Howl J, Rudge SA, Lavis RA, Davies L, Parslow RA, Hughes PJ, Kirk CJ, Mitchell RH and Wheatley M (1995) Rat testicular myoid cells express vasopressin receptors: receptor structure, signal transduction and developmental regulation Endocrinology 136 2206-2213

Knight TW (1974) A qualitative study of factors affecting the contractions of the epididymis and ductus deferens of the ram Journal of Reproduction and Fertility $4019-29$

Manning M, Cheng LL, Stoev S, Sawyer WH, Tribollet E, Barberis C, Wo NC and Chan WY (1995) Novel potent and selective antagonists and radioiodinated ligands for oxytocin and vasopressin receptors In Neurohypophysis: Recent Progress of Vasopressin and Oxytocin Research Exerpta Medics International Congress Series 1098 pp 21-38 Eds T Saito, K Kurokawa and S Yoshida. Elsevier Science BV. Amsterdam

NichoIson HD, Greenfield HM and Frayne J (1994) The effect of germ cell complement on the presence of oxytocin in the interstitial and seminiferous tubule fluid of the rat testis Journal of Endocrinology 143 471-478

Nicholson HD and Hardy MP (1992) Luteinizing hormone differentially regulates the secretion of testicular oxytocin and testosterone by purified adult rat Leydig cells in vitro Endocrinology 130 671-677

Nicholson HD, Swann RW, Burford GD, Wathes DC, Porter DG and Pickering BT (1984) Identification of oxytocin and vasopressin in the testis and in adrenal tissue Regulatory Peptides 8 141-146

NichoIson HD, Worley RTS, Guldenaar SEF and Pickering BT (1987) Ethan-1,2dimethanesulphonate reduces testicular oxytocin content and seminiferous tubule movements in the rat Journal of Endocrinology $112311-316$

Nicholson HD, Guldenaar SEF, Boer GJ and Pickering BT (1991) Testicular oxytocin: effects of intratesticular oxytocin in the rat Journal of Endocrinology $130 \quad 231-238$

Niemi M and Kormano M (1965) Contractility of the seminiferous tubule of the postnatal rat testis and its response to oxytocin Annales Medicinae Experimentalis et Biologiae Fenniae $\mathbf{4 3} 40-\mathbf{4 2}$

Pickering BT, Ayad VJ, Birkett SD, Gilbert CL, Guldenaar SEF, Nicholson HD, Worley RTS and Wathes DC (1990) Neurohypophysial peptides in the gonads: are they real and do they have a function? Reproduction, Fertility and Development 2 245-262

Pickering BT, Birkett SD, Charlton HM, Guldenaar SEF, Nicholson HD, O'Shaughnessy PJ, Swann RW, Wathes DC and Worley RTS (1986) Neurohypophysial peptides in the gonads. In Neuroendocrine Molecular Biology pp 231-237 Eds G Fink, AJ Harmar and KW McKerns. Plenum Press, New York

Roosen-Runge EC (1951) Motions of the seminiferous tubules of rat and dog Anatomical Record (Supplement) 153109

Russell L and Clermont V (1976) Anchoring device between Sertoli cells and late spermatids in rat seminiferous tubules Anatomical Record 185 259-278 
Setchell BP (1970) The secretion of fluid by the testes of rats, rams and goats, with some observations on the effects of age, cryptorchidism and hypophysectomy Journal of Reproduction and Fertility 23 79-85

Taylor GT, Weiss J, Frechmann T and Haller J (1985) Copulation induces an acute increase in epididymal sperm numbers in the rat Journal of Reproduction and Fertility 73 323-327

Van Haaster LH and De Rooij DG (1993) Spermatogenesis is accelerated in the immature Djungarian and Chinese hamster and rat Biology of Reproduction 49 $1229-1235$
Voglmayr JK (1975) Output of spermatozoa and fluid by the testis of the ram and its response to oxytocin Journal of Reproduction and Fertility 43 119-122

Worley RTS, Nicholson HD and Pickering BT (1985) Testicular oxytocin: an initiator of seminiferous tubule movement? In Recent Progress of Cellular Endocrinology of the Testis pp 205-212 Eds JM Saez, MG Forest, A Dazord and $J$ Bertrand. INSERM, Paris

Yeung WSB, Guldenaar SEF, Worley RTS, Humphrys J and Pickering BT (1988) Oxytocin in Leydig cells: an immunocytochemical study in Percoll-purified cells from rat testis Cell and Tissue Research 253 463-468 